\title{
Close, but not too close: social interactions among mother treehoppers
}

\author{
M. H. Richards ${ }^{1}$
}

Published online: 4 September 2020

(C) International Union for the Study of Social Insects (IUSSI) 2020

Treehoppers (Membracidae, Hemiptera) may be best known for their sometimes bizarre morphology and colouration, but they also exhibit interesting and varied maternal care. Eggs and juveniles are prime targets for predators and parasitoids, whereas adults have effective defenses, and many treehopper species exhibit substantial maternal care. Mothers often lay egg masses in slits that they cut into the underside of a leaf on their favoured host plant, inserting the eggs and then covering them with a secretion from their accessory glands. These simple structures are functionally equivalent to bird nests. In subsocial species, juveniles remain with their mother after hatching, and maternal care can be quite sophisticated. In many species, the pronota of adult females are modified as large shields under which their offspring can hide, and some of the baroque humps, bumps, and other extensions on their backs likely help to fend off aerial predators. Mothers facilitate larval feeding by cutting slits in plant tissues to make it easier for juveniles to suck up plant juices. Mothers even herd their offspring, calling stray juveniles back to the safety of the group (an interesting view of this behaviour: https://www.youtube.com/watch? $\mathrm{v}=\mathrm{Y} 0 \mathrm{oZk}$ GGIe0I).

When juveniles of treehoppers or other insects remain together or with their mother for prolonged periods of time, this sets the evolutionary stage for further social evolution. Recent studies on the treehopper, Alchisme grossa, in forests of the Andes have helped to delineate what these next possible steps in social evolution might be (Torrico-Bazoberry et al. 2014). Alchisme grossa mothers prefer to oviposit on host plants in the Solanaceae. Multiple mothers may oviposit on the same plant, but usually only a single mother oviposits on a leaf. Mothers remain with their offspring for varying amounts of time, with juveniles dispersing as early as the

M. H. Richards

mrichards@brocku.ca

1 Biological Sciences, Brock University, St. Catharines, ON, Canada third larval instar to as late as the fifth (and final) larval instar. When two females find themselves in close proximity, this creates opportunities for social interactions between families. Sometimes groups of juveniles coalesce. When this happens, one female may abandon her brood, and the other may end up guarding a mixed group that includes unrelated juveniles. Observations like these raise fascinating questions about the evolutionary significance of such behaviour. Is group formation simply an accident of proximity or is there some important adaptive function such as enhanced predator protection? Are neighbouring mothers related? Are juvenile herds composed of kin or do they also include non-kin?

To answer such questions requires detailed behavioural observations and genetic analyses of relatedness. In this issue, Urquizo and colleagues (2020) begin the process of teasing apart some of the classic social evolutionary hypotheses that explain such scenarios. Working in the cloud forest of Cochabamba, Bolivia, they observed individually marked A. grossa mothers and their brood, as well as interactions between mothers (referred to as primaries) and secondary females in close proximity. About a third of mothers received visits from one to as many as five different secondary females. Urquizo et al. suggest two very different hypotheses to explain such observations. Secondary females might be attempting to parasitize another female's maternal care by adding their own offspring to her brood. Alternatively, secondary females might be trying to form breeding groups in which females raise brood together. The evidence from this study mostly favours the brood parasitism hypothesis. Mothers aggressively attempted to repulse approaching secondary females by standing above their egg clutches, fluttering their wings, and buzzing, behaviours similar to those used to defend brood against predators. Moreover, genotype analyses of relatedness confirmed that brood were the direct offspring of their mother and unrelated to the secondary females. Most likely, primaries react aggressively to secondaries, because there is a cost to caring for larger numbers of brood. For instance, if a mother's offspring get pushed to 
the edge of the herd, they are more likely to be parasitized or predated (Camacho et al. 2014). Behavioural observations suggested that primaries are generally successful at keeping secondary females away from their brood, but cannot force them to leave altogether. In fact, some secondary females eventually laid their own clutches on the same host plant.

A host plant with multiple nesting treehoppers on different leaves is basically a nesting aggregation, which is certainly a looser social grouping than a colony of individuals that live in close proximity inside a single nest. Living in aggregations on the same host plant has some important advantages for $A$. grossa mothers, because larger female aggregations exhibit more effective brood defence against parasitoids (Camacho et al. 2014). It may be that the aggressive behaviour of treehopper mothers towards interlopers serves to regulate physical spacing among families, keeping breeding females far enough apart to avoid the costs of brood parasitism but close enough to benefit from enhanced predator protection or even dilution effects in larger groups of juveniles (Camacho et al. 2014). Since earlier studies suggest that families do sometimes coalesce into groups, there likely is environmental variation in the costs and benefits of close, but not-too-close nesting that awaits further investigation.

\section{References}

Camacho L, Keil C, Dangles O (2014) Factors influencing egg parasitism in sub-social insects: insights from the treehopper Alchisme grossa (Hemiptera, Auchenorrhyncha, Membracidae): Parasitism patterns in Alchisme grossa. Ecol Entomol 39:58-65. https://doi. org/10.1111/een.12060

Torrico-Bazoberry D, Caceres-Sanchez L, Saavedra-Ulloa D et al (2014) Biology and ecology of Alchisme grossa in a cloud forest of the Bolivian Yungas. J Insect Sci 14:169. https://doi. org/10.1093/jisesa/ieu031

Urquizo ON, Veliz D, Torrico-Bazoberry D et al (2020) Reproductive and brood-rearing strategies in Alchisme grossa (Hemiptera: Membracidae): genetic analyses of kinship relationships. Insect Soc. https://doi.org/10.1007/s00040-020-00776-3 